\title{
近十年来鄱阳湖区越冬白鹤种群数量与分布
}

\author{
单继红 ${ }^{1}$ ，马建章 ${ }^{1}$, 李言阔 ${ }^{2, *}$, 钱法文 ${ }^{3}$, 涂晓斌 4 \\ (1. 东北林业大学 野生动物资源学院, 黑龙江 哈尔滨 $150040 ; 2$. 江西师范大学 生命科学学院, 江西 南昌 $330026 ; 3$. 中国林业科学研究院森林 \\ 生态环境与保护研究所 国家林业局森林保护学重点实验室, 北京 100091; 4. 江西省野生动植物保护管理局, 江西 南昌 330046)
}

摘要：1998-2010 年, 该研究采用地面同步调查法在鄱阳湖区 64 个湖泊开展了越冬白鹤种群监测。结果表 明，鄱阳湖区分布有稳定的越冬白鹤种群，鄱阳湖区越冬白鹤种群数量年平均值为(3 108 1849$)$ 只, 2002 年冬季达 到最大值 4004 只; 从 2003 年开始鄱阳湖区越冬白鹤数量表现出一定的年际波动, 但变化幅度较小。共有 46 个湖 泊被记录到有白鹤活动。其中, 达到全球白鹤种群数量 $1 \%$ 标准以上的湖泊达 25 个; 白鹤数量接近或超过全球白 鹤种群数量的 $40 \%$, 即 1280 只个体以上的湖泊包括鄱阳湖国家级自然保护区内的大汉池、蚌湖和虫豆湖, 以及保 护区外的南湖。自然保护区涵盖了越冬白鹤的主要聚集湖泊。分布在自然保护区内的白鹤占鄱阳湖区越冬白鹤种 群总数量的 $(66 \pm 27.3) \%$ 。保护区外分布的白鹤数量虽然总体呈下降趋势, 但仍分布有一定数量的个体。

关键词: 鄱阳湖; 白鹤; 种群数量动态; 空间分布格局

中图分类号: Q145; Q915.865 文献标志码：A 文章编号：0254-5853-(2012)04-0355-07

\section{Population and distribution of the Siberian crane (Grus leucogeranus) wintering in the Poyang lakes over the past decade}

\author{
SHAN Ji-Hong ${ }^{1}$, MA Jian-Zhang ${ }^{1}$, LI Yan-Kuo ${ }^{2, *}$, QIAN Fa-Wen ${ }^{3}$, TU Xiao-Bin ${ }^{4}$ \\ (1. College of Wildlife Resources, Northeast Forestry University, Harbin 150040, China; 2. College of Life Science, Jiangxi Normal University, Nanchang \\ 330022, China; 3. Key Laboratory of Forestry Protection of State Forestry Administration, Research Institute of Forest Ecology, Environment and Protection, \\ Chinese Academy of Forestry Sciences, Beijing 100091, China; 4. Wildlife Service of Jiangxi Province, Nanchang 330046, China)
}

\begin{abstract}
Using simultaneous land surveys, we monitored the population size and spatial distribution of wintering Siberian cranes at 64 lakes around Poyang Lake between 1998 and 2010. The results showed that 46 lakes were inhabited by wintering cranes, and in 25 of those, the number of wintering cranes accounted for more than $1 \%$ of the Siberian cranes' global population. The lakes where over $40.0 \%$ of the global population, e.g. 1280 individuals, included Dachahu Lake in Jiujiang region, and Banghu Lake and Candouhu Lake in the Poyang Lake Nature Reserve. The average yearly population of the wintering Siberian crane in the Poyang lakes was $3108 \pm 849$, with the maximum of 4004 individuals in winter 2002. On the whole, there was no drastic fluctuation, but population numbers have shown considerable fluctuation since 2003. We also found the Poyang Lake Nature Reserve was the major wintering area of the Siberian crane, with over $60 \%$ of Siberian cranes wintering in the reserve since 2002 (except in 2006). Most of the inhabited lakes are covered in existing nature reserves, though some lakes outside the reserve were also considerably used by Siberian cranes.
\end{abstract}

Key words: Poyang lakes; Siberian crane; Population dynamic; Distribution

白鹤 (Grus leucogeranus) 又名西伯利亚鹤, 其全球种群现存仅约 3200 只个体，被 IUCN 红皮书 及中国濒危物种红皮书分别列为极度濒危及濒危 级物种, 同时也被列为我国国家 I 级重点保护物种 (China Wildlife Propagation Institution for Protection,
1989)。现存的白鹤可分为 3 个种群: 东部种群为数 量最大的种群, 主要在西伯利亚东北部繁殖, 中国 长江中游流域越冬; 中部种群, 仅 4 只个体, 主要 在西伯利亚库诺瓦特(Kunovat)河谷繁殖, 印度拉基 斯坦邦(Rajasthan)的克拉迪奥国家公园(Keoladeo

收稿日期: 2012-02-07; 接受日期: 2012-04-20

基金项目：白鹤 GEF 项目中国项目区(SCWP-China)

*通信作者(Corresponding author), 李言阔, 博士, 副教授, 从事动物生态学研究。E-mail: liyankuo@126.com

第一作者简介: 单继红, 女, 助理研究员, 主要从事野生动物保护与利用和自然保护区学研究。Email:shanjh2002@126.com 
National Park) 越冬; 西部种群, 仅 9 只个体, 主要 在俄罗斯西北部繁殖, 伊朗里海(Caspian sea)南岸 越冬(USGS, 2006)。

在我国长江中、下游的白鹤越冬地，鄱阳湖区 是全球最大的白鹤越冬区。1980 年冬我国科研人员 首次在鄱阳湖大湖池发现了 91 只白鹤越冬个体 (Zhou et al, 1981)。其后，一系列的相关研究表明鄱 阳湖区分布有数量较大的白鹤种群。Yan \& Ding (1988) 在鄱阳湖记录到的越冬白鹤种群数量逐年 增加, 由 1981 年的 140 只增加到 1987 年的 1609 只。据 1998 年鄱阳湖冬季调查，该区共发现 2526 只白鹤, 近年来江西鄱阳湖白鹤越冬种群数量达到 世界白鹤总数量的 $95 \%$ 以上( $\mathrm{Su}$ et al, 2000)。因此, 在鄱阳湖区开展白鹤种群的必要的保护和研究对 于这一濒危物种全球种群恢复无疑具有重要的意 义。由于鄱阳湖区湖泊众多, 有关白鹤种群的调查 主要集中在鄱阳湖保护区。为了全面掌握整个鄱阳 湖区越冬白鹤种群的数量与分布, 本研究对鄱阳湖 区 68 个湖泊进行了为期 11 年的白鹤种群监测, 以 期为该物种的有效保护和管理提供必要的基础 数据。

\section{1 研究地区概况}

鄱阳湖湿地是我国最大的淡水湖泊湿地, 也是 迁徙水鸟的重要越冬栖息地, 位于长江南岸, 江西 北部, 地理坐标为 $\mathrm{E} 115^{\circ} 49^{\prime} \sim 116^{\circ} 46^{\prime}, \mathrm{N} 28^{\circ} 11^{\prime} \sim$ $29^{\circ} 51^{\prime}$, 属亚热带湿润季风型气候, 热量丰富, 雨量 充沛，无霜期长，四季分明。年平均气温 17 $17.8{ }^{\circ} \mathrm{C}$, 年际变化不大。南北相差 $1{ }^{\circ} \mathrm{C}$ 左右。高值 区在南部, 低值区在北部。气温季节性变化明显, 无霜期平均为 $246 \sim 284 \mathrm{~d}$, 年平均降水量 1636.4 $\mathrm{mm}$, 年平均日照 $1702 \mathrm{~h}$, 高于 $10{ }^{\circ} \mathrm{C}$ 积温平均为 $5244 \sim 5666^{\circ} \mathrm{C}$, 年辐射总量为 $460 \sim 477 \mathrm{~kJ} / \mathrm{cm}^{2}$ (Wang, 2004)。

鄱阳湖是季节性过水湖泊、连河湖, 承接竷江、 抚河、信江、饶河、修水五大河的来水, 经调蓄后 经湖口进入长江, 流域面积 $16.2 \times 10^{4} \mathrm{~km}^{2}$, 是一个 完整的水系。同时, 鄱阳湖水位也受到长江来水的 影响, 长江水时有倒灌入湖现象。洪水季节, 鄱阳 湖水位高涨、湖面宽阔、一望无际。枯水季节, 鄱 阳湖水位下降, 洲滩出露, 湖水归槽, 蜿蜒一线。 洪、枯水期的水域面积、水容积相差极大。“高水 是湖, 低水似河, 洪水一片, 枯水一线” 是鄱阳湖区
的自然地理特征。

\section{2 方 法}

考虑到鄱阳湖区的实际情况和水鸟地面调查 的系统性以及调查数据统计分析的可比性, 1998-2010 年冬季鄱阳湖越冬水鸟调查均采用同 步调查计数法，即在同一时间内，定点、同步对湖 区越冬候鸟进行直接观察计数统计。调查时间为每 年的 1 月上旬，主要集中在 12 月 29 日一来年的 1 月 9 日, 要求天气晴朗, 以利于地面调查。具体调 查时间分别为 1999 年 1 月 7-11 日、2001 年 1 月 7 - 11 日、 2002 年 1 月 7-11 日、 2003 年 1 月 7一 11 日、 2004 年 1 月 7-11 日、 2005 年 1 月 7- 11 日、 2005 年 12 月 $27-31$ 日、2006 年 12 月 $27-31$ 日、 2008 年 1 月 $2-5$ 日、 2009 年 2 月 $11-15$ 日 和 2011 年 1 月 $10-13$ 日。

由于地面调查覆盖子湖泊数量多、调查范围 广、调查操作难度大, 共分为 44 个调查组, 每组 2 -3人。调查人员主要由环鄱阳湖 3 市 15 县(市区) 林业局野生动植物保护站的工作人员、鄱阳湖保护 区的工作人员以及江西师范大学和江西农业大学 研究人员组成。正式调查前, 每个调查组先抽调出 人员，进行野外调查培训，然后返回调查点分别参 加鄱阳湖区目标湖泊越冬水鸟的同步地面调查。

调查区域包括鄱阳湖区 3 市 13 县 (市、区)与 鄱阳湖国家级自然保护区管理局所辖区域内的 68 个子湖泊的水域和草洲 (图 1)。调查范围跨度整个 鄱阳湖区，基本覆盖鄱阳湖区大、小子湖泊、湖汉 和河口等区域。3 市 13 县(市、区)是指南昌、九江、 上饶 3 个设区市，以及南昌市管辖的新建、南昌、 进贤县，九江市管辖的庐山区、共青城、瑞昌市，都 昌、星子、湖口、彭泽、九江，上饶市管辖的余干 县和鄱阳县。

\section{3 结 果}

\section{1 种群数量}

11 年的监测结果表明, 鄱阳湖区分布有稳定的 越冬白鹤种群(图 2)。1998 年冬季一2010 年冬季, 鄱 阳湖区越冬白鹤种群平均大小为 $(3108 \pm 849)$ 只。种 群数量表现一定的波动, 但并无明显变化规律。白 鹤种群从 2000 年冬季记录到的 1791 只增长到 2002 年的 4004 只, 成为鄱阳湖区迄今为止最大的越冬 白鹤种群数量记录。2003 年冬季白鹤种群数量与 


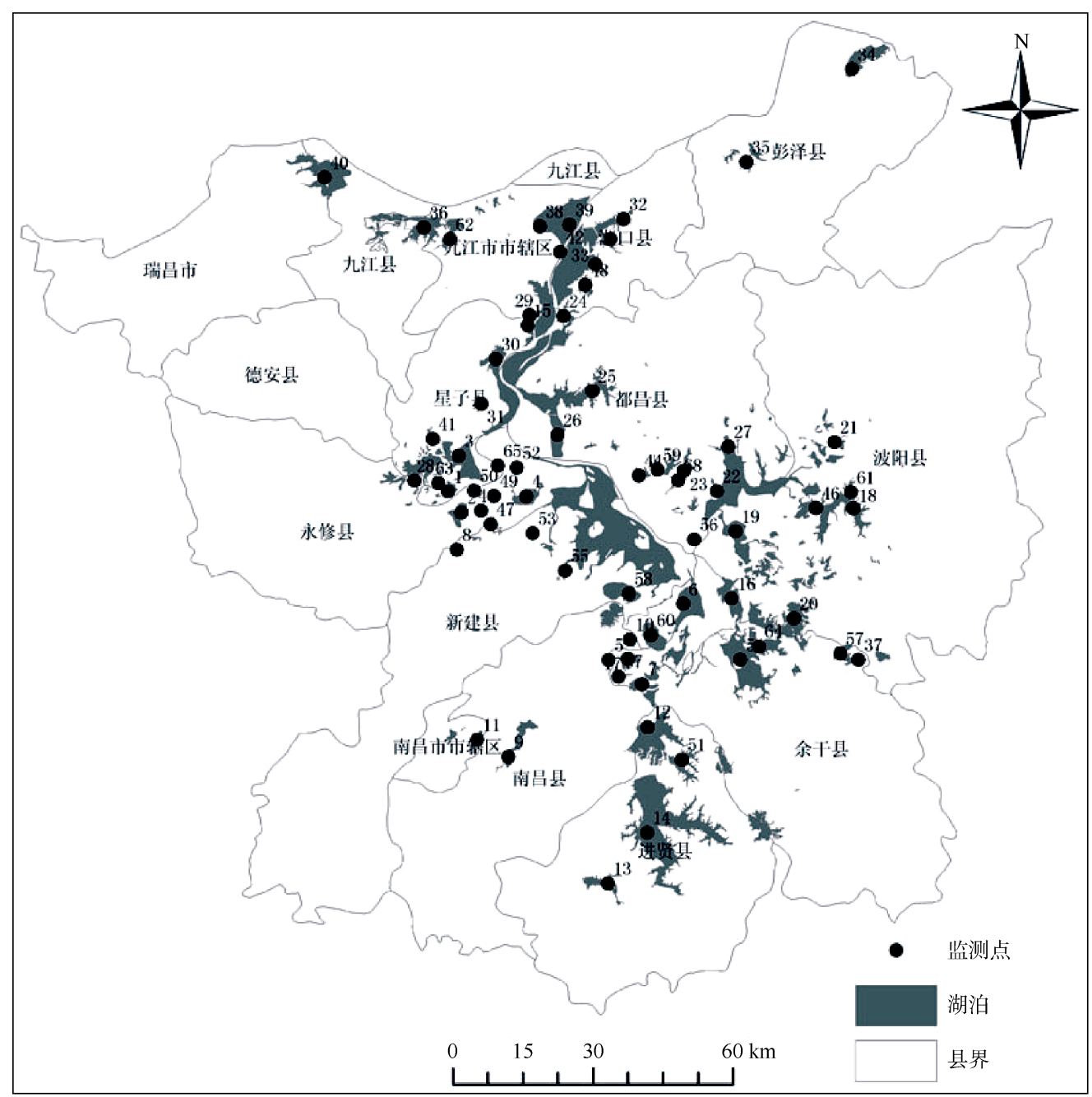

图 1 鄱阳湖区越冬白鹤种群监测湖泊位点示意图

Fig. 1 Map showing locations of the lakes involved in monitoring the wintering population of the Siberian crane in Poyang Lake (specific lakes are named in the following list)

1)沙湖 Shahu; 2) 大湖池 Dahuchi; 3) 蚌湖 Banghu; 4) 大汊湖 Dachahu; 5) 西湖(南昌县) Xihu (in Nanchang); 6) 东湖 Donghu; 7) 程家池 Chengjiachi; 8）芰湖 Linghu；9）瑶湖 Yaohu；10）三湖 Sanhu；11）艾溪湖 Aixihu；12）金溪湖 Jinxihu；13）青岗湖 Qinglanhu；14）军山湖 Junshanhu；15） 珠琳湖 Zhulinhu；16）南疆湖 Nanjianghu；17）林充湖 Linchonghu；18）内珠湖 Zhuhu；19）汉池湖 Chachihu；20）大莲子湖 Dalianzihu；21） 企湖 Qihu；22）长溪湖 Zhouxihu；23）花厘湖 Hualihu；24）高桥湖 Gaoqiaohu；25）新妙湖 Xinmiaohu；26）矶山湖 Jishanhu；27）西湖(都昌 县) Xihu (in Duchang)；28）南湖(共青城) Nanhu (in Gongqingcheng)；29）梅溪湖 Meixihu；30）十里湖 Shilihu；31）苶花池 Liuhuhua；32）北港湖 Beiganghu；33）泊洋湖 Boyanghu；34）太泊湖 Taibohu；35）芳湖 Fanghu；36）赛湖 Saihu；37）晚湖 Wanhu；38）芳兰湖 Fanglanhu；39）鞋 山湖 Gushanhu; 40) 赤湖 Chihu; 41) 寺下湖 Sixiahu; 42) 谷山湖 Gushanhu; 43) 常湖池 Changhuchi; 44) 砖塘湖 Huangjinzui; 45) 南港湖 Nanganghu; 46）外珠湖 Waizhuhu；47）象湖 Xianghu；48）㿝湖 Zaohu；49）中湖池 Zhonghuchi；50）朱市湖 Zhushihu；51）陈家湖 Chenjiahu；52）梅西 湖 Meixihu； 53）虫豆湖 Candouhu；54）插旗湖 Chaqihu；55）大伍湖 Dawuhu；56）对面山 Duimianshan；57）湛公湖 Zhangonghu；58）泥湖 Nihu; 59) 南溪湖 Nanxihu; 60) 三泥湾 Sanniwan; 61) 珠湖 Zhuhu; 62) 七里湖 Qilihu; 63 长湖 Changhu; 64) 南尖湖 Nanjianhu; 65) 苍湖 Canghu; 66）落脚湖 Luojiaohu； 67）南湖(余干县) Nanhu (in Yugan)； 68）输湖 Shuhu.

加粗的湖泊名为有白鹤分布记录的湖泊（The boldfaced lakes indicate Siberian crane was recorded in these lakes）。

2002 年基本持平, 为 3954 只。白鹤种群数量自 2003 年呈现一定的波动。2004 年冬季为 3119 只, 2005 年冬季增长到 3944 只; 2006 年冬季又降低到 2693 只, 而 2007 年冬季又增加到 3750 只; 2008 年仅 1627 只, 是近 11 年来的最低值; 2010 年冬季增加 到 3371 只。由于 2009 年冬季的调查开展于 2010
年 2 月 27 日, 调查时间较晚, 白鹤已经开始迁飞, 野外调查过程中仅记录到 133 只个体。

\section{2 空间分布}

在 68 个湖泊监测点中, 有 46 个湖泊被记录到 有越冬白鹤个体(图 1)。其中, 达到全球白鹤种群数 量 $1 \%$ 标准以上的湖泊达 25 个(表 1$)$, 按照这些湖泊 


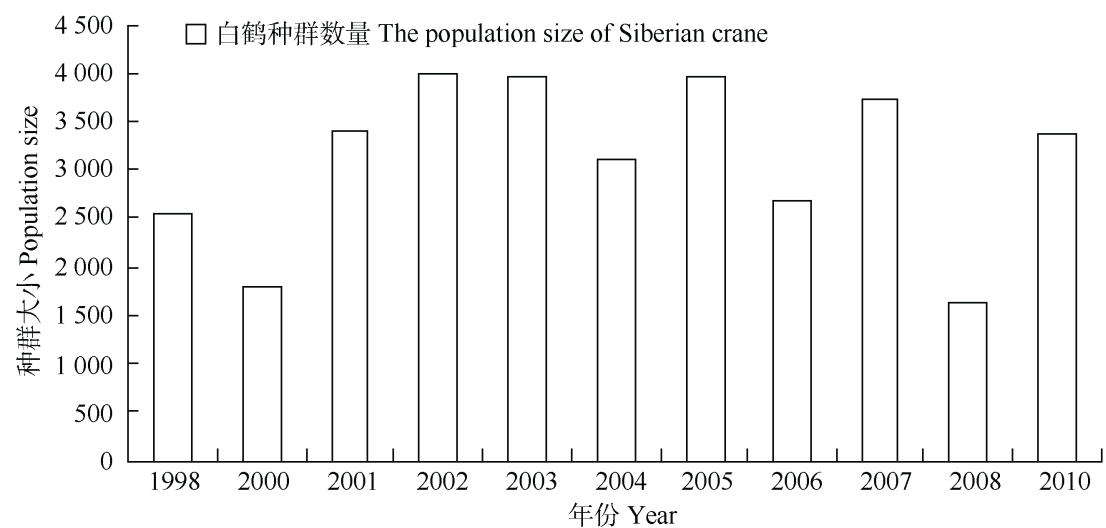

图 21998 - 2010 年冬季鄱阳湖区越冬白鹤种群数量变化

Fig. 2 Dynamics of the wintering Siberian crane population size in the Poyang Lake from 1998-2010

表 $11998-2010$ 年冬季鄱阳湖区白鹤数量超过全球白鹤种群 $1 \%$ 的湖泊

Tab. 1 The lakes with Siberian crane more than $1 \%$ of the Siberian crane population over the world

\begin{tabular}{|c|c|c|c|c|c|c|c|c|c|c|c|}
\hline \multirow{2}{*}{ 湖泊 Lakes } & \multicolumn{11}{|c|}{ 年份 Year } \\
\hline & 1998 & 2000 & 2001 & 2002 & 2003 & 2004 & 2005 & 2006 & 2007 & 2008 & 2010 \\
\hline 沙湖 Shahu & & & & & 96 & 82 & 136 & 116 & & & \\
\hline 大湖池 Dahuchi & & 346 & 136 & & 109 & & & & & & 44 \\
\hline 蚌湖 Banghu & 36 & & 700 & 2827 & 560 & 1916 & 2429 & 1376 & & 1275 & 1632 \\
\hline 大汉湖 Dachahu & & 36 & 1448 & & & 209 & 386 & & 3016 & & 72 \\
\hline 中湖池 Zhonghuchi & & & & & & & 36 & & & & \\
\hline 朱市湖 Zhushihu & & & & & & 125 & & & & & \\
\hline 蚕豆湖 Candouhu & & & & & 1823 & & & & & & \\
\hline 程家池 Chengjiahu & & & & & & 534 & & & & & \\
\hline 林充湖 Linchonghu & 400 & 45 & 220 & 230 & 230 & & 214 & & & & 83 \\
\hline 外珠湖 Waizhuhu & & & & & & & & & & & 389 \\
\hline 汉池湖 Chachihu & & & 61 & 304 & & & 92 & 136 & 127 & & 82 \\
\hline 大莲子湖 Dalianzihu & & & & 90 & & & 44 & 36 & 58 & & \\
\hline 企湖 Qihu & & & & 180 & & & 55 & 64 & 86 & & 76 \\
\hline 长溪湖 Zhouxihu & & & 287 & & & & & & & & \\
\hline 矶山湖 Jishanhu & & & & & & & & & 180 & 120 & \\
\hline $\begin{array}{l}\text { 南湖(共青城) } \\
\text { Nanhu(Gongqingcheng) }\end{array}$ & 1510 & 680 & 40 & 89 & 450 & 138 & 87 & 133 & 33 & & \\
\hline 梅西湖 Meixihu & 63 & & & & & & & & & 158 & 851 \\
\hline 蓼花池 Liuhuchi & & 190 & & & & & & & & & \\
\hline 赛湖 Caihu & 108 & & & & 47 & & & & & & \\
\hline 赤湖 Chihu & & 50 & 35 & 80 & 50 & & & & & & \\
\hline 陈家湖 Chenjiahu & & & & & & & & 600 & & & \\
\hline 插旗湖 Chaqihu & & & 63 & & & & & & & & \\
\hline 南疆湖 Nanjianghu & & 160 & 282 & & 470 & & & & & & \\
\hline 珠湖 Zhuhu & & & & & & & 203 & 126 & 142 & & \\
\hline 南尖湖 Nanjianhu & & 200 & & & & & & & & & \\
\hline 花庙湖 Huamiaohu & & & & & & & & & & & 51 \\
\hline
\end{tabular}

历年白鹤数量记录的最大值排序, 依次为大汉湖 (3016 只)、蚌湖(2827 只)、䖯豆湖(1823 只)、南湖
(共青城, 1510 只)、梅西湖(851 只)、陈家湖(600 只)、 程家池(534 只)、南疆湖(470 只)、林充湖(400 只)、 
大湖池(346 只)、长溪湖(287 只)、珠湖(203 只)、南 尖湖(200 只)、苶花池(190 只)、企湖(180 只)、矶山 湖(180 只)、汉池湖(136 只)、朱市湖(125 只)、沙湖 (116 只)、赛湖(108 只)、大莲子湖(90 只)、赤湖 $(80$ 只)、插旗湖(63 只)和中湖池 (36 只)。在这些湖泊内 历年记录到的白鹤平均数量为 $(388 \pm 631)$ 只。白鹤 数量接近或超过全球白鹤种群总数量的 $40.0 \%$, 即 1280 只个体以上的湖泊包括九江市境内的南湖 (1510 只，1998 年冬)、鄱阳湖自然保护区内的大汉 池(1448 只, 2001 年冬; 3016 只, 2007 年冬)、蚌湖 (2827 只, 2002 年冬; 1916 只, 2004 年冬; 2429 只, 2005 年冬; 1376 只, 2006 年冬; 1275 只, 2008 年冬)
和虫豆湖(1823 只, 2003 年冬)。

鄱阳湖区的 64 个湖泊监测点, 每年冬季均记 录有白鹤活动的湖泊为 $11 \sim 27$ 个, 平均 18 个。 11 年的监测调查中有 12 个湖泊超过 6 次被记录有白 鹤分布(图 3), 可见这些湖泊是白鹤的重点活动区。 其中, 南湖 (共青城) 和大莲子湖在 11 年的调查监 测中每年都被观察到有白鹤分布, 平均数量分别为

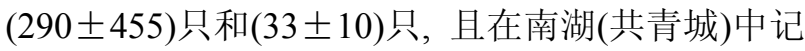
录到的白鹤数量差异较大, 1999 年有 1510 只个体, 而 2008 年仅 8 只个体。而赤湖除 2010 年末记录到 白鹤外, 其他年份均记录到白鹤群体, 但数量相对 较少, 约 $(25 \pm 8)$ 只。

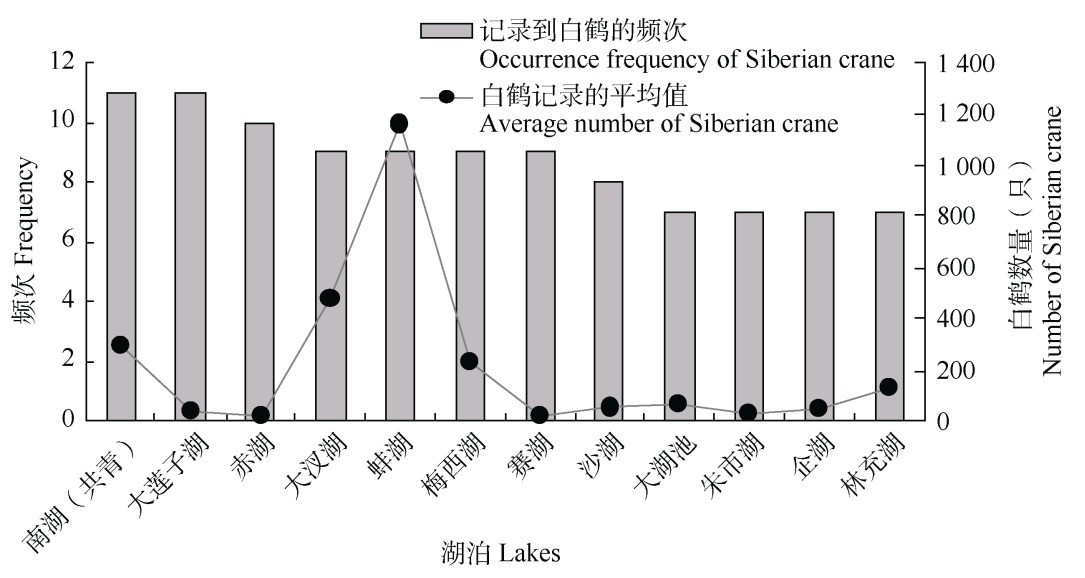

图 3 1998-2010 年冬季鄱阳湖区超过 6 年记录到有白鹤分布的湖泊的白鹤被记录次数及其平均白鹤数量

Fig. 3 Frequencies and average number of wintering Siberian cranes in lakes where Siberian cranes were recorded for more than 6 years from 1998 to 2010

大汉湖、蚌湖和梅西湖分布的白鹤群体数量最

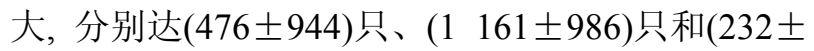
475)只, 且这 3 个湖泊中白鹤集大群的现象较普遍。 从各湖泊中的白鹤数量来看, 每年冬季白鹤在鄱阳 湖呈聚集分布, 即在少数湖泊中集群分布, 少量个 体零星分散在其他湖泊。如 2007 年冬季, 占鄱阳湖 区越冬白鹤数量 $80.4 \%$ 的个体分布在鄱阳湖自然保 护区内的大汉湖。除 2000 年冬季越冬白鹤分布相 对均匀(在九江市共青城的南湖发现 680 只个体, 占 当年越冬白鹤数量的 $38.0 \%$ ) 以外, 其他年份越冬白 鹤均表现出在少数湖泊内集中分布的特点, 在一个 湖泊中的个体比例达 $40.0 \sim 78.4 \%$ 。

在鄱阳湖区，自然保护区涵盖了越冬白鹤的主 要聚集湖泊。分布在鄱阳湖国家级自然保护区、南 矶湿地国家级自然保护区和都昌湿地候鸟自然保 护区内的白鹤年平均种群数量达(2 126 11046$)$ 只,
占鄱阳湖区越冬白鹤种群总数量的 $(66.0 \pm 27.3) \%$ (图 4)。其中，鄱阳湖国家级自然保护区内分布的白 鹤数量最大, 占鄱阳湖区越冬白鹤总数量的 $(62.6 \pm$ $26.1) \%$ 。从 2000 年开始, 除 2006 年冬季鄱阳湖国 家级自然保护区内白鹤数量仅占鄱阳湖区白鹤总 数量的 $28.6 \%$, 其他年份均超过 $65.0 \%$ 。2008 年冬 季鄱阳湖国家级自然保护区内的白鹤数量甚至达 到鄱阳湖区白鹤总数量的 $88.9 \%$ 。保护区外分布的 白鹤数量虽然总体呈下降趋势, 但仍分布有一定数 量的个体。1998 年冬和 2000 年冬季多达 $93.6 \%$ 和 $77.0 \%$ 的白鹤在调查期间被记录到在保护区外活动, 其后， 2001 年冬季一2006 年冬季，监测期间分布 在保护区外的白鹤占鄱阳湖区白鹤种群数量的比 例降低到 $(28.3 \pm 5.4) \%, 2007$ 年和 2008 年冬季更是 仅有 $9.5 \%$ 和 3.0\%的白鹤在监测期间分布于保护区 外, 但 2010 年冬季监测期间保护外的白鹤比例增 


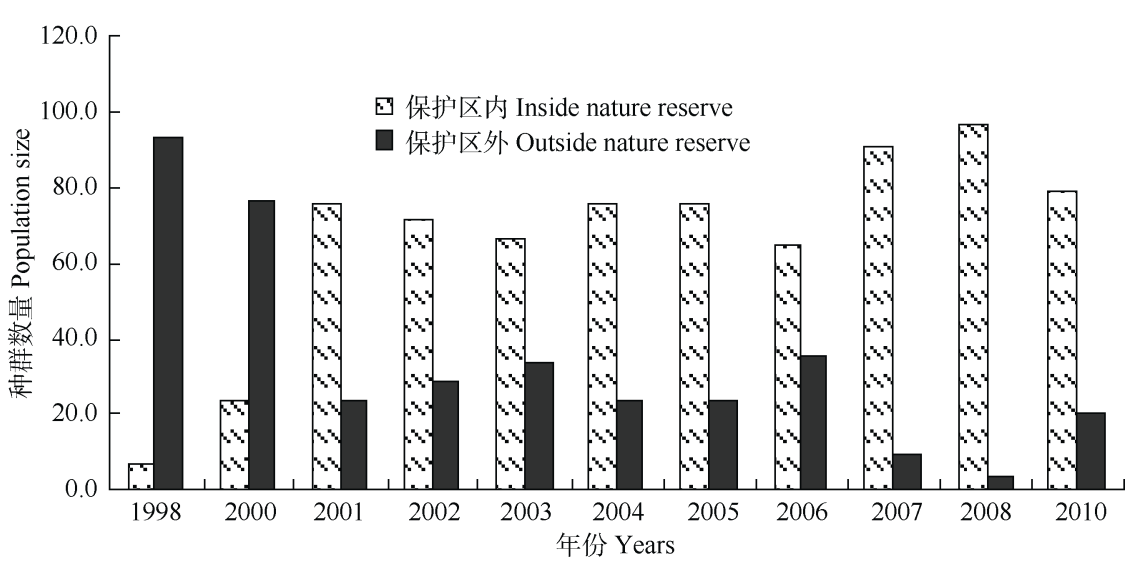

图 4 1998-2010 年冬季鄱阳湖区白鹤种群区域分布动态

Fig. 4 Distribution of wintering Siberian cranes inside and outside nature reserves in the Poyang lakes from 1998-2010

加到 $21.0 \%$ 。

\section{4 讨 论}

我国长江中、下游分布有全球主要的白鹤越冬 种群，其中鄱阳湖区是全球最大的白鹤越冬地。该 区白鹤种群数量的变化可以在很大程度上反映出 全球白鹤种群的数量动态。从 2000 年冬季开始白 鹤种群数量逐渐增加, 2001-2003 年、2005 年和 2007 年冬季鄱阳湖区白鹤数量均超过了 3200 只, 即目前估计的全球白鹤种群数量, 这表明全球白鹤 种群数量在 2001-2007 年间整体呈增长趋势。但 是, 从 2004 年开始, 环鄱阳湖区白鹤越冬个体数量 年际波动较大， 2008 年冬季达到近 10 年来的最低 值, 仅 1627 只。但是, 这并不意味着全球白鹤种群 数量发生巨大波动, 因为 2010 年又监测到 3371 只 白鹤在鄱阳湖越冬。由于 2008 年 1 月江西省遭受 了严重的冰雪冻灾, 鄱阳湖区的冰冻灾害可能在一 定程度上影响到 2008 年冬季鄱阳湖区白鹤越冬种 群的数量或者分布。

本研究为期 10 年的监测数据表明, 鄱阳湖区 已建的自然保护区是白鹤越冬的重要区域, 为白鹤 种群的保护奠定了良好的基础。尤其是鄱阳湖国家 级自然保护区, 作为越冬白鹤的主要聚集地, 从 2001 年开始, 除 2006年冬季, 鄱阳湖国家级自然保 护区内的越冬白鹤数量均超过鄱阳湖区白鹤越冬 种群数量的 $65.0 \%$ 。南矶湿地国家级自然保护区和 都昌省级候鸟保护区的建立将更多的重要白鹤栖 息地(如矶山湖、长溪湖、花庙湖)囊括在了保护区 内。越冬白鹤在鄱阳湖国家级自然保护区内的这种 集中分布，一方面有利于对该区域的越冬白鹤进行
巡护监测, 加大对该越冬群体的保护; 另一方面, 这种大规模的集群一旦受到致命性流行疫病感染、 冰冻灾害等恶劣气候袭击、被偷猎分子投毒或栖息 地剧烈变化等, 都将对种群产生严重影响, 甚至带 来毁灭性损害(Su et al, 2000; Wen \& Zeng, 2008)。

虽然自然保护区覆盖了主要的白鹤越冬湖泊, 但是目前仍有一些湖泊(如: 赤湖)尚未列入任何保 护区内, 且面临较大地人为干扰。本研究发现, 自 然保护区外的一些湖泊对越冬白鹤同样具有不可 忽视的重要性，监测期间每年有 $(34.0 \pm 27.3) \%$ 的 白鹤被记录到在保护区外的湖泊中活动。在 25 个 白鹤数量超过全球白鹤种群 $1 \%$ 的湖泊中, 有 18 个 位于鄱阳湖国家级自然保护区外，这些湖泊分布相 对分散, 在白鹤越冬种群及其栖息地的保护和管理 工作中应予以重视。

虽然近年来通过宣传教育、自然保护区建设和 候鸟专项保护行动等措施的执行, 鄱阳湖区候鸟保 护管理工作步入了良性循环。但是, 作为白鹤的重 要越冬生境, 这些湖泊同时又是当地社区居民的主 要经济来源之一。采砂、渔业捕捞、水产养殖和洲 滩畜牧业养殖等人类生产经营活动都在一定程度 上不可避免地对越冬白鹤的食物资源和生境造成 不利影响, 解决社区经济发展与白鹤栖息地保护之 间的矛盾仍然是鄱阳湖区越冬白鹤种群保护工作 必须面对的问题。利用天网或投毒捕杀越冬水鸟的 现象也未从根本上消除(Ye, 2000)。加强保护力度, 规范湿地资源开发利用时间、尺度和空间位置, 规 范当地群众利用资源的方式和数量仍是白鹤保护 工作中的重点(Guo et al, 2006)。 


\section{参考文献:}

China Wildlife Propagation Institution for Protection. 1989. The Law of Wild Animal Protection of People's Republic of China[M] // List of Wild Animals Under National Protection. Beijing: China Legal Press. [中国野生动植物保护司. 1989. 中华人民共和国野生动物保护法 // 国家重点保护野生动物名录. 北京: 中国法制出版社.]

Guo YR, Xie LY, Huang ZQ. 2006. The protect countermeasure of wetland based on winter migrant bird's community characteristic. J Anhui Univ: Nat Sci, 30(3): 84-90. [郭英荣, 谢利玉, 黄志强. 2006. 基于群落特 征的湿地候鸟保护对策. 安徽师范大学学报: 自然科学版, 30(3): 84-90.]

Su HL, Lin YH, Li DQ, Qian FW. 2000. Status of Chinese cranes and their conservation strategies. Biol Sci, 8(2): 180-191. [苏化龙, 林英华, 李 迪强, 钱法文. 2000. 中国鹤类现状及其保护对策. 生物多样性, 8(2): 180-191.]

U. S. Geological Survey (USGS). 2006. The Cranes Status Survey and Conservation Action Plan: Siberian Crane (Grus leucogeranus). http://www.npwrc.usgs.gov/resource/birds/cranes/grusleuc.htm.

Wang XH. 2004. Wetland Ecosystem Assessment of Poyang Lakes[M].
Beijing: Science Press. [王晓鸿. 2004. 鄱阳湖湿地生态系统评估. 北京: 科学出版社.]

Wen SB, Zeng NJ. 2008. Suggestions on wetland and migratory bird monitoring of Poyang Lake national nature reserve[J]. Jiangxi For Sci Technol, (2): 54-55. [文思标, 曾南京. 2008. 对鄱阳湖保护区湿地与 候鸟监测的几点建议. 江西林业科技, (2): 54-55.]

Yan L, Ding TM. 1988. The survey on Siberian crane population wintering in Poyang Lakes of Jiangxi Province[J]. Chn J Zool, 23(4): 34-36. [严 丽, 丁铁明. 江西鄱阳湖区白鹤越冬调查. 动物学杂志, $23(4)$ : 34-36.]

Ye YL. 2000. The police of Poyang Lake Nature Reserve destructed a organization of illegally hunting wintering migratory birds[J]. Wildlife, (2): 29. [叶永麟. 2000. 江西鄱阳湖保护区派出所摧毁一个特大毒 害珍禽候鸟的团伙. 野生动物, (2): 29.]

Zhou FZ, Ding WN, Wang ZY. 1981. A large flock of White Cranes (Grus Leucogeranus) wintering in China[J]. Acta Zool Sin, 27(2): 179. [周福 璋, 丁文宁, 王子玉. 1981. 发现大群白鹤在中国越冬. 动物学报, 27(2): 179.] 